\title{
Temperature measurements in thermal-vacuum tests for spacecraft qualification - possibilities for infrared thermography
}

\author{
by Daniel Döring*, Peter Jens Hein*, Christian Spiessberger** \\ * IABG mbH - Space Test Centre, Einsteinstrasse 20, 85521 Ottobrunn, Germany, doering@iabg.de \\ ** edevis $\mathrm{GmbH}$, Handwerkstr. 55, 70565 Stuttgart, Germany
}

\begin{abstract}
Spacecraft and their sub-systems are submitted to rigorous qualification tests in order to eliminate failures during launch and operation. These include thermal-vacuum testing to simulate the in-orbit conditions of high vacuum and extreme temperatures. During such tests, temperature values on hundreds of locations across the spacecraft are acquired using contact temperature sensors (standard). An alternative option is the integration of industrial-standard thermography into the harsh space testing environment.

This paper compares both options regarding ease of handling, cost, temperature range, measurement accuracy, and influence of the measurement on the thermal state.
\end{abstract}

\section{Introduction}

Spacecraft and their sub-systems are submitted to rigorous qualification tests before launch to ensure they can cope with the conditions during launch and operation. This is usually done on each and every satellite as well as on component level, as in-orbit failure of small parts can quite possibly result in a total loss of mission [1]. The specialized business of space simulation testing is either done by the manufacturers themselves, space agencies (NASA, ESA, JAXA, etc.) or by specialized independent technical service companies like IABG in Ottobrunn, Germany.

The testing includes the examination of the spacecraft's properties (mass, centre of gravity and moments of inertia), its resilience to mechanical stress (noise, shock and vibration testing), electromagnetic properties measurements and performance testing of the payload.

A key group of these tests is thermal-vacuum testing (thermal balance, thermal distortion, solar simulation, etc.) to simulate the in-orbit conditions of high vacuum, extreme temperatures and solar radiation. These are needed to prove that the thermal control system of the spacecraft is able to keep all subsystems at their safe working temperatures. In addition, the detailed thermo-mathematical model of the spacecraft is verified by analyzing the temperature reaction in a real thermal-vacuum environment [2].

The "product" of such tests is the measurement of hundreds of spacecraft temperatures. The default mode to do this is the manual application of contact temperature sensors. A new option is the integration of industrial-standard thermography into the harsh space testing environment.

This paper describes both ways of temperature data acquisition and investigates their advantages and limitations regarding ease of handling, cost, temperature range, measurement accuracy, and influence of the measurement on the thermal state.

\section{Space Simulation at IABG}

\subsection{Test Facilities}

IABG operates thermal-vacuum test chambers of different sizes with different specialized functions. Amongst them are a simple workhorse for component testing $\left(2 \mathrm{~m}\right.$ diameter, -180 to $\left.+180^{\circ} \mathrm{C}\right)$, a specialized low-temperature / high cleanliness chamber for optical instrument qualification $(2.5 \mathrm{~m}$ diameter, ISO Clean Class $5,10 \mathrm{~K}$ helium cooling capability, [3]), a $3 \mathrm{~m}$ chamber for high thermal loads (IR testing of solar power generators) and large subsystem tests, and finally the large "Weltraumsimulationsanlage" (WSA, space simulation test facility, $6.8 \mathrm{~m}$ diameter), featuring a sun simulation system and a motion simulator to manipulate the orientation of the spacecraft during testing [4]. All these chambers are operated at pressures below $10^{-5} \mathrm{mbar}$ and at extreme temperatures (temperature bandwidth $-261^{\circ} \mathrm{C}$ to + $180^{\circ} \mathrm{C}$ ), environmental conditions that non-specialized electronic components would not survive without a protective container. 


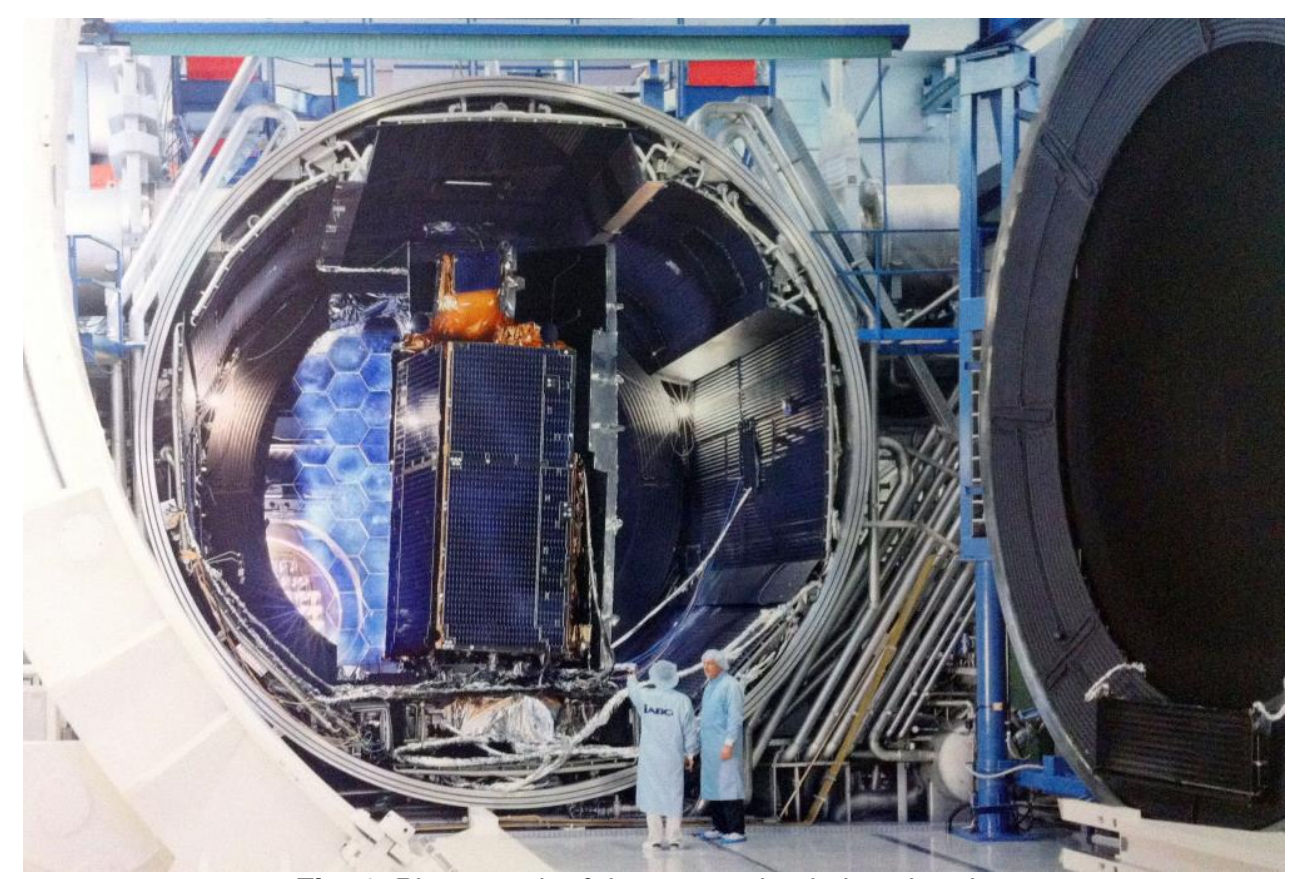

Fig. 1. Photograph of the space simulation chamber.

\subsection{Description of a typical system level qualification test}

A major milestone in the flight qualification campaign for a spacecraft or functional subsystems is thermalvacuum testing. To give an impression of the scope of a spacecraft or large subsystem test, which is the frame in which the thermography-integration is operated, here is some typical data:

- Operating pressure: $<10^{-5} \mathrm{mbar}$

- Temperature: $-180^{\circ} \mathrm{C}$, achieved by liquid nitrogen pumped through the wall elements ("shroud") inside the chamber

- Illumination of the spacecraft by wide-spectrum near parallel light with properties close to those found in orbit ("solar simulation", $1.4 \mathrm{~kW} / \mathrm{m}^{2}, 6000 \mathrm{~K}$ color temperature including IR and hard UV)

- $\quad$ Test time (facility operation): 2 - 6 weeks

- $\quad$ Time for the space simulation chamber to reach high vacuum and cryogenic temperature, so the actual testing can begin: $24 \mathrm{~h}$ (test interruptions to fix unreliable components are highly depreciated)

- $\quad$ 24/7 operation by 2-3 staff in 3-shift rotation

- 100 - 1000 temperature measurement channels (usually TCs)

- $\quad$ Time to integrate the spacecraft into the test chamber and to verify the correct operation of all sensors: 1-2 weeks

- Size of a customer test team (engineers, scientists, administration, co-located at IABG for the time of a test campaign): $10-50$

While a typical test house like IABG basically provides the operation of the facility and thus the space environment, the actual qualification test is run by the customer, remotely operating the spacecraft and its subsystems. Among these is the temperature control system dedicated to keeping the temperature of all other components within their safe (operational and non-operational) limits, as well as the diverse satellite payloads (communication equipment, earthobservation sensors, etc.).

In this context, a full-fledged thermography system with two infrared (IR) cameras integrated in vacuumprotection containers is "yet another ground support equipment" to be installed and - if necessary - developed.

\section{Methodology}

\subsection{Temperature Measurement Using Thermocouples}

The physical basis of using thermocouples (TCs) for temperature measurements is the temperature-dependant thermo-electric force generated at the interface between two metals. The voltage can be tapped by having the measurement junction (e.g. Cu to CuNi for type T TCs) at a to-be-determined temperature and the reference (or cold) junction ( $\mathrm{CuNi}$ to $\mathrm{Cu}$ ) at a well-known reference temperature. For details we would like to refer to the standard literature [6]. 


\subsection{1/qirt.2016.027}

The default way of acquiring temperatures in space testing is the use of stick-on TCs. This process includes [7]:

- $\quad$ Preparation of the TC

- Soldering of high-vacuum proof extension cables to the TC

- Stacking of the TC assembly: High vacuum adhesive tape, adhesive transfer tape (double-sided), TC, covering with adhesive tape;

- perforation of the stack to improve venting (avoid formation of bubbles when pumping down to high vacuum)

- $\quad$ Application of the TC to the spacecraft

- Cleaning of the surface

- Application of the TC assembly

- If applicable: Application of a surface emissivity adaptation

- Application of a strain relief

- $\quad$ Routing of cables

$\circ$ Guide (and fix) the TC cable along the specimen surface

- Collect the cables to bundles

- Guide the bundle to the exterior of the spacecraft $(\sim 3-5 \mathrm{~m})$

Pinning of TC cable to its respective connector

Extend the cable to a chamber bulkhead $(+5 \mathrm{~m})$

Vacuum feed-through (guide electrical connections from vacuum to ambient side)

- Extend to data acquisition system

- Data acquisition configuration

- Name all channels

- Load correct calibration curve

- Configure data acquisition frequency and storage

This manual process that has to be performed by skilled and trained personnel to ensure the reliability of the sensor during weeks-long testing, combined with the material cost for the single use sensor and the other specialized materials drives the recurring cost for each temperature measurement point. This in fact limits the number of temperature measurement points and thus the spatial resolution of the acquired temperature map.

While this way of temperature measurement is state-of-the-art, there are some test objects where wired contact sensors are not an appropriate or convenient solution:

- $\quad$ on very light structures (e.g. vacuum multi-layer insulation made from $20 \mu \mathrm{m}$ polymer foil), where the heat conducted via the cable would dominate the measured temperature

- on sensitive surfaces (e.g. vacuum-deposited thermal control surfaces) that would suffer from the application-removal of the adhesive tape (physical) or adhesive residue

- $\quad$ on high-temperature surfaces: the removable adhesive-based methodology is limited to $\sim 230^{\circ} \mathrm{C}$ due to melting / decomposition of the adhesive [5]

For some of these situations, the non-contact thermal imaging can be a solution.

\subsection{Integration of IR Thermography}

IABG is not the first space test centre that has integrated state-of-the-art thermal imaging into thermal vacuum testing. ESA's European Space and Technology Centre (ESTEC) in Noordwijk, The Netherlands, often sets the unofficial reference standard for new (non-standardized) methods in space qualification testing. One such innovation was the introduction of thermal imaging for high-temperature tests of components for European research missions [8]. Some key properties of this system are:

- Use of high-end cameras (cryogenic quantum detector technology)

- $\quad$ Custom-built camera containers

- $\quad$ Hermetically sealed containers with vacuum feed-throughs for all electrical connections

- $\quad$ Stand-alone temperature control

- $\quad$ Pressure monitoring of containers

- $\quad$ Tilted windows to avoid narcissus effect (to be more precise: a camera mount inside the container that tilts the camera axis against the container axis / window normal)

IABG as a commercial test house had to focus on a commercially viable solution that still meets the actual thermography requirements of our customers by adapting standard industrial products to the special requirements of the space testing environment. Thus implementation of a suitable thermography system focussed on a simple and costeffective solution that relies strongly on available parts and the test facility's control systems. IABG was supported by edevis $\mathrm{GmbH}$, Stuttgart, regarding IR camera technology and application as well as in the critical design review. The key design choices were derived from the above considerations and the need to implement the system in a very short time frame. They are:

- Use of an industrial automation camera (FLIR A655sc) with uncooled microbolometer detector, longwave optics (8-12 $\mu \mathrm{m})$, with specific advantages (+) and disadvantages (-) 


\subsection{1/qirt.2016.027}

+ moderate investment cost

+ lower power consumption, significantly less exhaust heat

+ wide range of operating temperatures $\left(-15\right.$ to $\left.+50^{\circ} \mathrm{C}\right)$

+ wide range of optics

+ remote-controlled motor focus

+ compact size

+ flexible power supply (12-24 V DC)

+ Single GBit Ethernet link for image data and control

+ basically unlimited un-interrupted operation

+ usable sensitivity at low $\left(>-20^{\circ} \mathrm{C}\right)$ temperatures

- slightly reduced noise equivalent temperature difference (NETD; $50 \mathrm{mK}$ )

- moderate detector resolution (640 x 480 pixel)

- limited effective frame rate (micro bolometer detector not suited for high-speed applications)

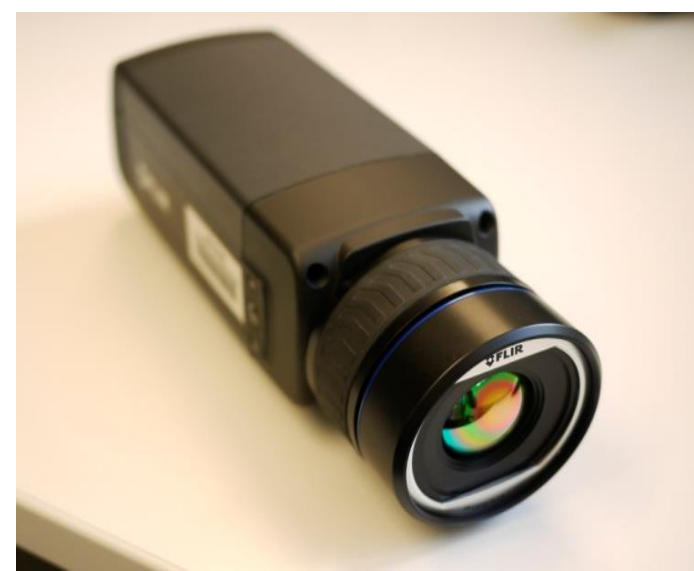

Fig. 2. Industrial automation camera

- Non-tilted IR window

Using a camera with an uncooled detector, there is no visible back-reflection of the detector at the window ("narcissus effect"). The inside of the camera container that is still back-reflected into the IR image (producing a small temperature offset, which has to be cancelled by an end-to-end calibration) is at a relatively homogeneous temperature. Thus we decided to go for the advantages of a non-tilted window: Smaller size, simpler container design, larger field of view - especially for our wide-angle lens $\left(90^{\circ}\right.$ field-ofview), an elimination of the narcissus effect is geometrically impossible.

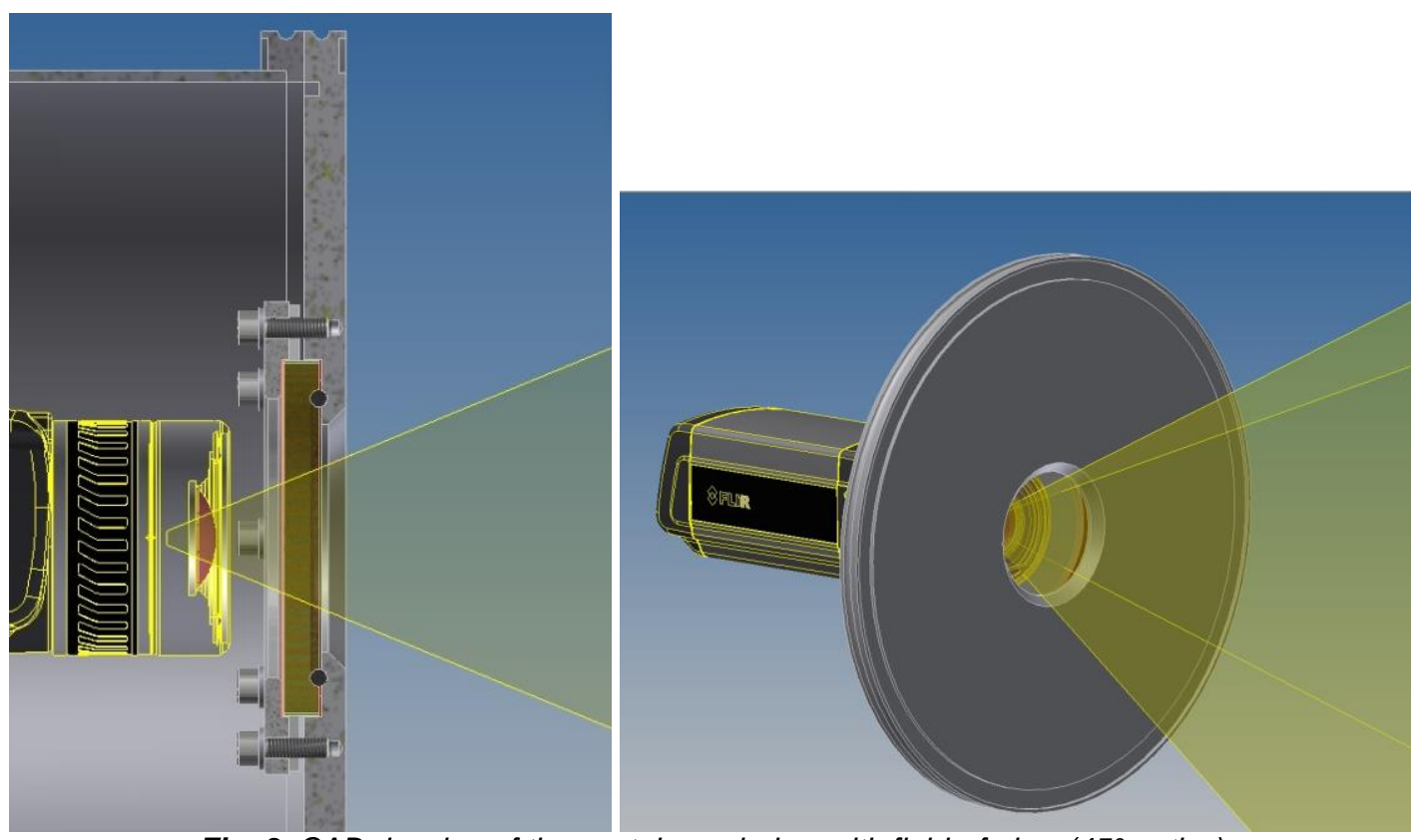

Fig. 3. CAD drawing of the container window with field-of-view ( $45^{\circ}$ optics) 


\subsection{1/qirt.2016.027}

The actual window was acquired as bare zinc sulfate disk, as this increased the degrees of freedom in container / window design and thus enabled a fall-back on IABG's standard design for optical windows at the atmosphere / high vacuum interface. Zinc sulfate was chosen as a compromise between optical properties, toxicity (avoiding e.g. Germanium) and cost. Although the zinc sulfate was not equipped with a longwave antireflective surface coating and transmission losses (reflection + absorption) were estimated to $30 \%$, influence on image quality and thermal data was surprisingly low.

- "Umbilical Cord Container"

The inside of IABG's camera container is connected to the atmosphere outside the thermal vacuum chamber using a single $40 \mathrm{~mm}$ stainless steel flexible tube. This tube not only ensures a constant pressure inside the container, it also contains all other connecting lines:

- Purge line: Supplying a constant, low-volume flow of dry air, to remove excess heat (if necessary) and to avoid condensation of moisture on the container window.

- Power supply line: 24 V DC (regular laboratory power suppy)

- GBit Ethernet for camera control and thermal imaging data

- $\quad$ Strong facility integration

Temperature sensors and electrical heaters were applied to the outer (vacuum) side of the container, as temperature data acquisition channels and heater power lines (with loopback control) are easily available in our thermal vacuum chambers. So for temperature control (which in the most common test situations means heating of the container) is performed using existing infrastructure.

- Use of OEM Software

As the software distributed with the IR camera (FLIR Research IR, Version 3.4) already provides most of the features needed for the intended operation, including the calculation of temperatures from raw IR data with correction of a number of influences (using an algorithm not disclosed by FLIR), this software was chosen. Typical data acquisition was either the recording of videos (25 fps) for visually interesting / highly dynamic test sequences of few minutes or the continuous storage of one IR frame each minute for the full test duration of several weeks.

Further features of the system that are driven by the thermal-vacuum environment (and not a personal design philosophy) are:

- $\quad$ Multi-Layer insulation (MLI): The container is covered with 10-layer vacuum insulation made from polyester foil made highly reflective with vacuum deposited aluminium (VDA Mylar), to reduce the radiative flux from / to the container to a minimum

- $\quad 100 \%$ high-vacuum compatible materials for all outside elements (container material, window seal, heaters, thermocouples, MLI, adhesive tape)

- $\quad$ Adjustable mounting to align the camera field of view with the test specimen

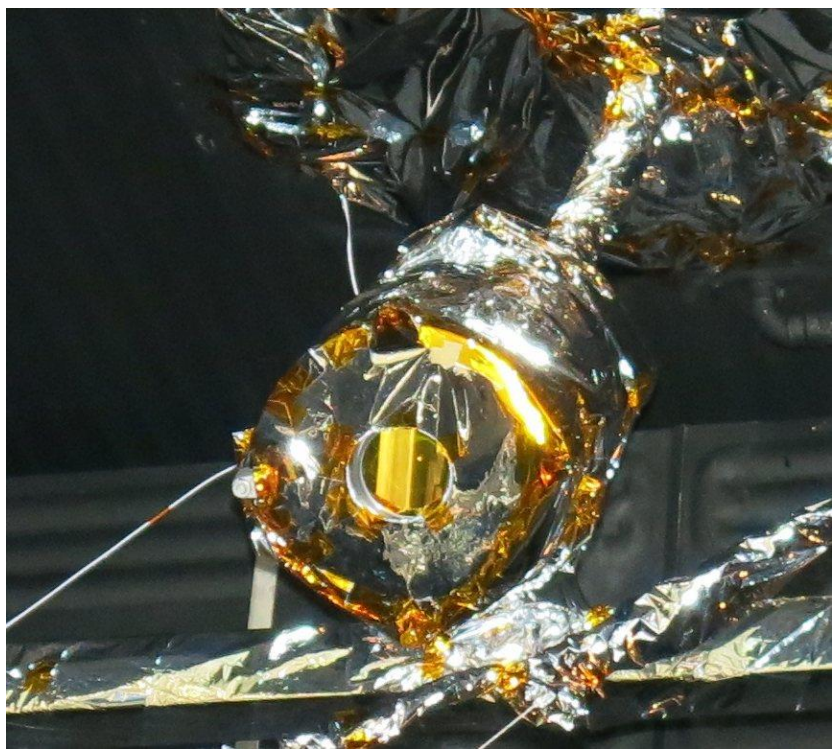

Fig. 4. Integrated camera container. Only the IR window and MLI are visible. 


\subsection{1/qirt.2016.027}

\subsection{Temperature calibration strategy}

The authors are fully aware of the fact that getting absolute temperature values from IR camera data is a difficult task at best - even more so in the context of space qualification / thermal vacuum testing. The special challenges are:

- Transmission loss / back reflection on window

- Extreme environmental conditions ('room temperature' around the specimen is typically at $-180^{\circ} \mathrm{C}$ )

- Uncertain emissivities: Beyond the typical error involved when using literature values for an object's emissivity, as well as the possibility of angle-dependant emission, in space testing one has the additional problems, that

$\circ$ a) emissivity often changes with the transfer from ambient to vacuum conditions, e.g. due to loss of adsorbed water,

- b) emissivities are rarely constant for the full temperature band studied

- c) manufacturers of spacecraft / space structures make strong use of selective surfaces whose emissivity is extremely wavelength-dependant, e.g. second surface mirrors for thermal control.

Thus a purely analytical calibration approach was deemed futile and abandoned. Our course of action to temperature measurement using the IR camera system was therefore based on a combination of best estimate and individual corrections: initially, the corrections (reflected temperature, external optics temperature / transmission, surface emissivity, etc.) available in the FLIR ResearchIR were used based on literature values or rough measurements. These settings were applied in the calibration run as well as the actual spacecraft qualification test. For calibration, we recreated the test environment (vacuum, cryogenic environment) with a calibration test specimen usually in the form of a thick aluminium plate equipped with electrical heaters, reference temperature sensors and well-bonded patches of the actual surface materials expected in the test. Stepwise temperature ramps of the test specimen over the full operational range provide correction curves from IR camera / software temperature read-out to actual specimen surface temperature.

The difference between the actual temperature and the "best estimate" was usually below $10{ }^{\circ} \mathrm{C}$ in the -40 to $+150{ }^{\circ} \mathrm{C}$ range. As it was found impossible to integrate this correction function into the ResearchIR software, it had to be applied manually during post-processing of the IR data. The quality of the IR signal at temperatures below the low temperature limit as taken from the data sheet $\left(-20^{\circ} \mathrm{C}\right)$ was surprisingly good. This is assumed to be the result of the cryogenic environment where the background radiation of the shrouds $\left(-180^{\circ} \mathrm{C}\right)$ in the frequency band of the camera is virtually zero and we thus have no temperature noise caused by reflected IR radiation.

One alternative is the in-situ approach, using one or more contact TCs on the visible surface and tweaking the software parameters for the TC and IR temperature readout to match. This is most useful if the IR image is used to study detailed temperature distributions of more or less homogeneous surfaces. 


\section{Method Comparison}

The following matrix presents our comparison of the two temperature measurement methods, ranging from "++" for very good / highly suited to "--" for very poor / unsuitable.

\begin{tabular}{|c|c|c|}
\hline & Contact TCs & IR Thermography \\
\hline $\begin{array}{l}\text { Absolute temperature } \\
\text { measurement } \\
\text { accuracy }\end{array}$ & $\begin{array}{l}<0.5 \mathrm{~K} \text { possible } \\
\text { (mK accuracy possible for individually calibrated } \\
\text { platinum resistance thermometers) }\end{array}$ & $\begin{array}{l}\text { o/- } \\
\sim 10 \mathrm{~K} \text { "best estimate approach" } \\
2-3 \mathrm{~K} \text { with prior surface-specific calibration } \\
\text { (limited by camera calibration / stability) }\end{array}$ \\
\hline $\begin{array}{l}\text { Relative temperature } \\
\text { resolution (/NETD) }\end{array}$ & $<10 \mathrm{mK}$ & $\sim 50 \mathrm{mK}$ \\
\hline Sampling speed & $\begin{array}{l}\text { typical sampling: } 1 / \mathrm{min} \\
\text { "high speed": } 1 / \mathrm{s} \\
\text { (thermal processes in space testing are usually so } \\
\text { slow, that } 1 / \mathrm{min} \text { is fast enough) }\end{array}$ & $\begin{array}{l}\text { Sampling speeds between } 50 \mathrm{~Hz} \text { and } 1 / \mathrm{min} \\
\text { New possibilities for highly dynamic processes } \\
\text { currently not regarded. }\end{array}$ \\
\hline Spatial resolution & $\begin{array}{l}\text { Physical size limit } \sim 1 \mathrm{~cm} \\
\text { Practical limit: Installation / material cost limits to } \\
\text { few tenths to hundreds of channels }\end{array}$ & $\begin{array}{l}640 \times 480 \text { pixels, } \\
\text { resulting in } \sim 1-10 \mathrm{~mm} \text { resolution for typical specimen }\end{array}$ \\
\hline Low temperature limit & $\begin{array}{l}\text { Regularly used to }-196^{\circ} \mathrm{C} \\
\text { Suitable down to } \sim 10 \mathrm{~K} \\
\end{array}$ & $\begin{array}{l}\text { Good signal to noise above }-20^{\circ} \mathrm{C} \\
\text { Usable signal down to }-40^{\circ} \mathrm{C}\end{array}$ \\
\hline High temperature limit & $\begin{array}{l}\text { O/+ } \\
\text { Removable adhesive up to }+230^{\circ} \mathrm{C} \\
\text { Screw-on or inorganically bonded up to } 2000^{\circ} \mathrm{C}\end{array}$ & $\begin{array}{l}\text { Standard configuration }+600^{\circ} \mathrm{C} \\
\text { With filters: No real limit }\end{array}$ \\
\hline $\begin{array}{l}\text { Highly sensitive } \\
\text { surfaces }\end{array}$ & Needs good thermal contact & Non-contact method \\
\hline $\begin{array}{l}\text { Temperature } \\
\text { falsification risk }\end{array}$ & $\begin{array}{l}\text { TC can alter surface emissivity and thus change } \\
\text { the actual temperature of the point of } \\
\text { measurement if no } \varepsilon \text {-matching is performed }\end{array}$ & No influence on surface \\
\hline $\begin{array}{l}\text { Range of surface } \\
\text { properties }\end{array}$ & $\begin{array}{l}\text { Adaptation to surface by covering with high/low } \\
\text { emissivity tapes }\end{array}$ & $\begin{array}{l}\text { Usable results only for high emissivity surfaces }(\varepsilon> \\
0.5) \\
\text { Application of "virtual TCs" (patches of high-emissivity } \\
\text { tape) possible } \\
\text { For } \varepsilon<0.9 \text { corrections for reflected IR emissions should } \\
\text { be performed (highly complex) }\end{array}$ \\
\hline $\begin{array}{l}\text { Performance in high } \\
\text { thermal flux } \\
\text { environments }\end{array}$ & $\begin{array}{l}\text { o } \\
\text { Temperature of the sensor may not represent the } \\
\text { object temperature due to gradient over the } \\
\text { adhesive film assembly }\end{array}$ & $\begin{array}{l}\text { o } \\
+: \text { IR emission is radiated from true specimen surface. } \\
\text { - Corrections due to reflected IR radiations may be } \\
\text { necessary }\end{array}$ \\
\hline Calibration & $\begin{array}{l}\text { +++ } \\
\text { Standardized calibration process } \\
\text { Traceable to reference standards }\end{array}$ & $\begin{array}{l}\text { Calibration of the camera by manufacturer } \\
\text { End-to-end calibration for individual surfaces (complex, } \\
\text { time-consuming) }\end{array}$ \\
\hline Accessibility & $\begin{array}{l}\text { TCs can be placed anywhere on or inside the } \\
\text { spacecraft }\end{array}$ & $\begin{array}{l}\text { Surface-only } \\
\text { One perspective only (extension by multiple cameras } \\
\text { and/or mirrors possible) }\end{array}$ \\
\hline $\begin{array}{l}\text { Installation effort / } \\
\text { recurring costs }\end{array}$ & Tedious manual process & $\begin{array}{c}+ \\
\text { No work on specimen required }\end{array}$ \\
\hline Investment cost & $\begin{array}{l}\text { o } \\
\text { High-precision data acquisition system (scanner), } \\
\text { vacuum-poof chamber feed-throughs, } \\
\text { sophisticated data handling and storage system }\end{array}$ & $\begin{array}{l}\text { P } \\
\text { Price of the IR camera itself is only a small part of the } \\
\text { development / manufacturing cost of the protective } \\
\text { container and facility integration. }\end{array}$ \\
\hline $\begin{array}{l}\text { Risk of sensor } \\
\text { damage }\end{array}$ & $\begin{array}{l}\text { ++ } \\
\text { Prediction for specimen temperatures effectively } \\
\text { prevents sensors to get out of safe operating limits }\end{array}$ & $\begin{array}{l}\text { Damage of detector possible by intense IR sources in } \\
\text { the field of view / reflected into the camera (infrared } \\
\text { illumination lamps, solar simulator) }\end{array}$ \\
\hline
\end{tabular}




\section{Application}

The IR Camera System now available at IABG has been successfully used in tests of large subsystems (up to two IR cameras to cover solar-illuminated front and cold back surface), as well as in a system-level satellite test. Unfortunately, the data created as result of tests on interesting specimen (that is: real spacecraft or subsystems) is the property of the test customer and the authors have not yet been able to get permission to use real test images for publication.

Figure 4 shows images acquired during a blank test (dry run of the facility will all equipment installed, but without the test specimen) during cool-down of the chamber. The temperature distribution indicates of the direction of flow of cold nitrogen gas through the shrouds (temperature-controlled wall elements). The rectangular frame structure that is still very warm (bright yellow) in both images is an aluminium dummy representing the size and location of the item to be tested later. Each image also shows the other camera container (easy to spot above the circular door in the left image, less visible on the right).
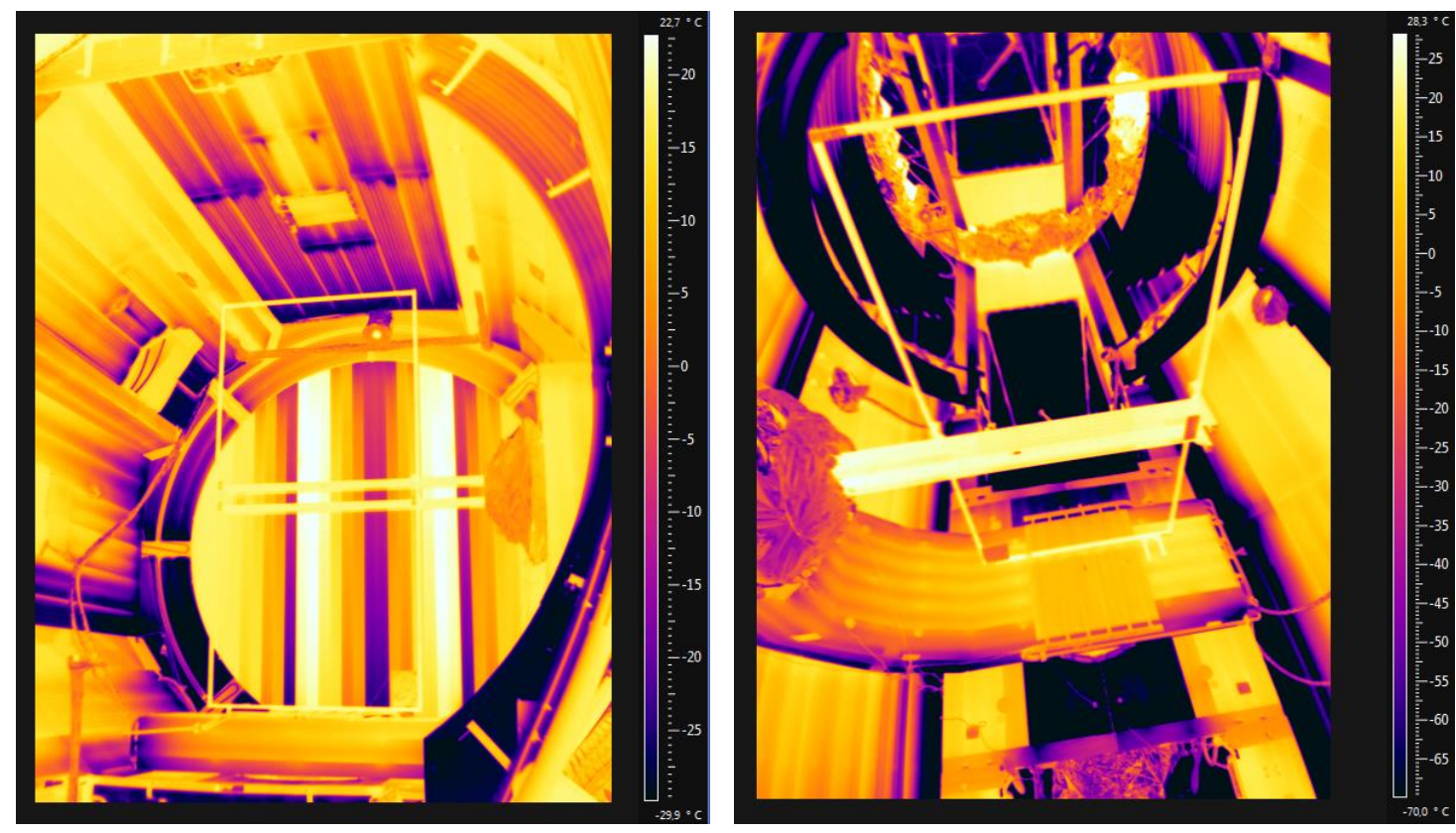

Fig. 5. Thermal images of the space simulation chamber during shroud cool-down, looking towards the chamber door (left) and towards the solar simulator mirror (right).

As a commercial company we expect increasing demand for facility-integrated thermography capability. In the context of tests in the small chambers we are currently evaluating the integration of small low-end cameras to reduce the space needed for the thermography system.

\section{Conclusion}

Based on extensive experience in space simulation testing / facility operation, the heritage of prior integration of (visible range) optical systems into the facilities and the thermography-specific consulting by EDEVIS, IABG was able to design, manufacture and test a thermography system integrated to space testing (TIST) in a very tight time frame and on a limited budget. Many design choices were done on a more pragmatic than academic basis, with the result of a system that is easy to handle and delivers high-quality data in a stable way proving us right. The IR camera system was successfully used in large subsystem and satellite qualification tests.

The way the system is designed and implemented makes it suitable for high-temperature tests (up to $600^{\circ} \mathrm{C}$ ) although the experimental verification of this application is still pending. 


\section{REFERENCES}

[1] Ley W., Wittmann K., Hallmann W.: "Handbuch der Raumfahrttechnik”, 3rd Edition; Carl Hanser Verlag, München, 2008.

[2] Döring, D., Ulfers, H.: "Mathematical Models of IABG Thermal-Vacuum Facilites", European Conference on Spacecraft Structures, Materials \& Environmental Testing, Braunschweig, Germany, 2014.

[3] Söllner B.: "Low Temperature Thermal Vacuum Test Facility for Optical Instruments", European Conference on Spacecraft Structures, Materials \& Environmental Testing, Noordwijk, The Netherlands, 2012.

[4] Schindler R.: "TN-TR30-2591 Facility Description Space Simulation / Thermal Vacuum test Facility WSA/TVA"; Issue 2.0, IABG Document, 2015.

[5] Hein, P, Döring, D., Lentz, D.: "Concepts and Methods for Application of Very High Temperatures Inside Standard Thermal-Vacuum Test Facilities”, European Conference on Spacecraft Structures, Materials \& Environmental Testing, Braunschweig, Germany, 2014.

[6] Bernhard, F. (Ed.): "Handbuch der Technischen Temperaturmessung", $2^{\text {nd }}$ Edition, Springer Verlag, 2014.

[7] K. Buczek: "TN-TR30-1911: Procedure for Attachment of Thermocouples to Test Specimen for Thermal Tests", Iss. 5 Rev. 0, Internal handling procedure, IABG, 2014

[8] G. Casarosa et al.: "Development and qualification of an Infrared camera system for Thermographic applications in TV-TB conditions", 25th Aerospace Testing Seminar, 2009 